\title{
Selected aspects of sustainable tourism and their application in the operation of accommodation and catering facilities in the Moravian-Silesian Region
}

\author{
Jana Stuchlikova ${ }^{1}$ and Milena Botlikova ${ }^{1, *}$ \\ ${ }^{1}$ Silesian University in Opava, Faculty of Philosophy and Science, 74601 Opava, Czech Republic
}

\begin{abstract}
Given the global nature of tourism and the increased mobility potential of the population, the sustainability of tourism has been a topical issue for many years. The paper aims to map aspects of sustainable tourism and the extent of their use in the operation of accommodation and catering facilities in the regional environment; the research was conducted in the Moravian-Silesian Region, which is very specific on several levels. There are a number of large industrial enterprises that have a negative impact on the environment; on the other hand, there are countless natural, cultural, technical and other attractions, which are reflected in the increasing traffic to this destination. Due to the restructuring of the industry, the region is clearly showing its ecological tendencies, and the region is trying to present itself as an environmentally friendly region. In the context of tourism, there is a need to provide quality, eco-friendly accommodation, and catering services. The paper contains an overview of indicators based on the European system of indicators in the field of tourism and their specific impacts primarily on the environment. There is also an overview of whether and to what extent operators of accommodation and catering facilities in the Moravian-Silesian Region apply tools used mainly in connection with ecological behaviors, such as waste sorting, wastewater treatment, water management, and energy savings. For the analysis and comparison, were used primary data from controlled interviews with operators of monitored facilities, and secondary data from the Czech Statistical Office.
\end{abstract}

\section{Sustainable tourism}

Tourism is one of the fastest-growing industries in the world [1]. Many authors deal with the issue of sustainable tourism development in the professional literature. Some of them study the very essence of sustainability and adequacy of development; others focus on its aspects, impacts or assessments. Every person perceives adequacy differently. The term 'sustainable development' has many forms in the literature, and there is no uniformly accepted definition. At the same time, there is no set of indicators that could determine whether this is sustainable development or whether the principle has been violated. In general, the professional community agrees mainly that the development of tourism cannot be planned and assessed in isolation. Tourism is influenced by many processes and activities, as well as operating in a particular environment that shapes it. [2]. For example,

*Corresponding author: milena.botlikova@fpf.slu.cz 
the definition of the European Parliament emphasizes the development aspect itself. According to this institution, sustainable development is about improving living standards and human well-being within the limits of ecosystem capacity while preserving natural values and biodiversity for present and future generations. Building sustainable tourism development is also addressed in the 2030 Agenda, which emphasizes the so-called managerial ecology of sustainable tourism [3]. The basic pillars of sustainable development are social, economic and, last but not least, environmental.

\subsection{Sustainable tourism - selected aspects}

Over the past few decades, policymakers and marketers have become increasingly aware that the long-term development and sustainability of tourist destinations require clear guidance and direction. The incentive for sustainable tourism development has become increasingly urgent as a result of dual climate change trends and the accumulation of global tourism. [4]. In this context, the efforts of multinational organizations and research teams to develop uniform measurement methodologies that can be carried out by monitoring the impact on the environment of all tourism-related activities are increasingly important.

\subsubsection{Impacts of tourism on the environment}

Tourism, like any other socio-economic phenomenon, affects the human environment in both positive and negative ways. The very nature of tourism as such implies that it has an impact on the rate and composition of the use of ecosystem services. The environmental impact of tourism is less pronounced compared to other economic sectors (in particular industry), has a different course and nature, and is often intangible. According to international experience, they have a longer-term character, especially when influencing the socio-cultural and natural environment of destinations. In many cases, unregulated tourism leads to many negative effects associated with excessive consumption of non-renewable resources and environmental degradation, in particular concerning traffic flows, construction and operation of accommodation and waste disposal, energy intensity, noise, congestion, etc.

Elimination of these impacts or reversal of undesirable development tends to be more demanding financially and organizationally, and the later the systematic and comprehensive approach to tourism begins. The negative impacts of tourism are not only seen at the visitor's place of residence (i.e. destination) but also affect the more extensive area, especially about the transport of visitors and tourists [2].

Incidental costs are associated with the indirect (secondary) impacts of tourism. They are also sometimes referred to as negative externalities. According to Fretchtling [5], negative externalities lead to a change in the quality of life of residents of the destination and costs financed by the public administration. Responding to negative externalities varies and residents can choose one of the options to cope with these externalities:

- accept the reduced quality of life caused by these externalities,

- mitigate the decline in the quality of life through public spending,

- Introduce fees and taxes directly to destination visitors.

The following table 1 gives an overview of the different impacts of tourism on the local environment, which are not primarily economic. However, it will eventually translate into increased public finance requirements.

\subsubsection{Evaluation of sustainable development}

The evaluation of sustainable development should be a complex interdisciplinary activity [6]. The complexity of the issue of sustainable development is determinedly by the decisive involvement of a wide range of experts, local government, population, entrepreneurs and other persons and entities. 
However, it is essential to evaluate on a regular and systematic basis. Mid-Term evaluation, which is carried out in the course of (e.g., half) the planned activity, examines the first results, their relevance and the degree of achievement of the anticipated goal. Policies and ex-post evaluation - we use it to retrospectively assess the success of adopted policies and plans [7].

In practice, qualitative approaches are usually used to describe sustainable development, most often in the form of SWOT analysis and quantitative approaches, the essence of which is to strive for accurate, quantifiable measurement of the state and development of individual components or areas of sustainable tourism development.

In this case, we carry out monitoring and evaluation using indicators that describe their purpose well. The great advantage of using indicators is the objectivity of this approach and the relatively easy interpretation of observation results. Below are key UNWTO indicators

\subsection{Specifics of sustainable tourism in the hotel industry}

The continual development of tourism is experiencing a rapid deterioration of the environment, to which the hotel industry is also primarily involved. Tourists are searching not only for traditional tourist destinations, but increasingly for places where the necessary infrastructure is not built, leading, among other things, to the construction of transport infrastructure and, last but not least, accommodation facilities, resulting in water, waste, energy, congestion and next. Clearly defines the key and optional indicators for environmental impacts that are include in the list, including criteria and reference indicators [8]. The list includes indicators such as transport, climate change, waste and water management, wastewater treatment.

Due to the considerable extent of the issue, we focus on waste management in accommodation and restaurants, especially in connection with food waste, which is a global problem, including costly disposal [9]. While more experts are beginning to address this issue, there is no standardized method for quantifying food waste [10].

Studies carried out are usually in short time series have a different methodology and data are collected only in the sub-goals, which means that you can not objectively compare the outputs. Nevertheless, it is possible to generalize both the causes of food waste and the possibilities of reducing food waste. Virtually all researches and practice have shown that food waste is a vital problem for many hotel companies, with important implications for developing competitive strategies, implementing environmental practices and emphasizing CSR efforts.

The main factors leading to food waste include over-ordering food for guests, inventory management errors, food preparation staff errors, and food safety practices. Possible strategies for reducing food waste include employee training, using the right equipment, better bid planning procedures, accurate forecasting of demand, and implementation of efficient storage practices [11]. Inexpensive and simple measures in the form of a rearrangement of the dining room and menu tables at a hotel, in times of high demand, when tourists are loading more than they can eat, will reduce food waste and hence the cost of providing it [12].

At the same time, it is important to motivate consumers to reduce food waste and, last but not least, synergies by governments, responsible institutions and individual businesses in the supply chain, including wholesale, retail, and restaurant. [13].

Managerial Approaches [14] focus on liquidation rather than prevention Lack of state support, imperfect legislation, irresponsible consumer behavior and limited internal resources prevent more advanced management approaches. Targeted policy interventions are necessary to increase the efficiency of food waste management within this sector. These interventions aim to strengthen business commitments and facilitate changes in consumer behavior in the environmental field. An alarming finding of the authors of a study aimed at 
identifying the ecological footprint in developing countries where food waste is increasing due to urbanization, increased income and tourist traffic, for example in Lhasa for 20112015 by up to $39.7 \%$ [15].

Food waste has significant harmful economic, environmental and social impacts. The scale and complexity of the global food waste problem have brought it to the forefront of the environmental agenda. Food delivery, food consumption, and food waste generation should be studied together in order to fully understand where, and most importantly, why food waste arises [16].

\section{Problems of food waste in the operation of accommodations and catering facilities}

More than $1 / 3$ of all foods in the world are thrown away or destroyed, although some of them are still fit for human consumption.

In the Czech Republic alone, we produce approximately 729 thousand tonnes of food waste per year. So, for each of us, we have 5.3 tons of food in our lives, which is 26,500 schnitzels. Wastes occur on all the links in the food chain, i.e. farmers, processors, subcontractors, traders and consumers [13].

With discarded food, you deplete energy, soil, water and human labor that you can use to produce food. Most discarded foods end up in landfills, leading to the formation of methane, the strongest greenhouse gas that contributes to climate change. We all bear the cost of not only the food we throw away, but also indirectly the depletion of natural resources and the negative environmental impact of agricultural production.

However, food waste, which led to the loss of money and wasted human labor, is not only an ethical or economic issue but also an environmental problem. Food production, processing, and distribution have significant environmental impacts. Food production is costly for limited natural resources such as water and energy.

Agriculture is one of the most demanding sectors in terms of water consumption. The environmental impacts of agricultural production include the generation of $\mathrm{CO} 2$ emissions, the loss of biodiversity of agricultural land, its pollution and water pollution. Most of the discarded food ends up in landfills. The decomposition of food waste in the absence of air produces methane, which has a $20 \mathrm{x}$ stronger greenhouse effect than carbon dioxide emissions. Discarded or depreciated food contributes 1.5 million tonnes of carbon dioxide per year [17].

The EU has set itself the objective of reducing 'food waste' as one of the main objectives in the coming period. This commitment is a UN commitment to halving food waste by 2030 in the context of sustainable development. In a relatively wealthy Europe, 55 million people find it challenging to find a primary livelihood, while more than $20 \%$ of the food produced is thrown or confused saturation of the needy. Reducing food waste is therefore not a marginal topic at a time when agricultural land is becoming less and more, and more people are growing.

As far as gastronomy is concerned, this is about $12 \%$ of waste worldwide; this is a similar percentage to that of $11 \%$ in primary production, $19 \%$ in industry, but more than $5 \%$ in the food retail and wholesale sectors. The most waste is $53 \%$ in households. Efforts in this area are also aimed at the motivation catering providers, who should see a waste reduction as a cost reduction.

Disposal of food waste is an increasingly expensive service paid to accredited companies to whom we are obliged to deliver waste. We also have VAT in the waste that we can deduct, for example, when it is handed over to the food bank. In addition to the usefulness for the whole company, it is good to realize that our customer also feels sustainable development as an added value for our services. 
Waste minimization can serve as a free marketing tool. In order to minimize the volume of food waste, should be taken the following steps: prevention, waste leakage, - handover of food stoppers - use of gastro-waste as feed - recycling - disposal. [18]. All the above measures could be applied in hotels and restaurants in the Czech Republic, including the Moravian-Silesian Region.

\subsection{Approaches to facilities in the Moravian-Silesian Region to waste management}

The Moravian-Silesian Region is one of the 14 higher territorial self-governing units in the Czech Republic, located in the northeast. It has approximately 1.2 million inhabitants. There are four Euroregions in the region - Beskydy, Praděd, Silesia and Těšín Silesia. In the past and this is true even today, North Moravia mainly focused on heavy industry. Unfortunately, due to economic reforms and subsequent economic crises, the once relatively prosperous region has become the area with the lowest employment in the Czech Republic and the poor environment.

Today the situation is improving. In the context of today's good economic situation, unemployment here is only $3.1 \%$, but it is still one of the highest in the country. According to the CSO, there are currently 615 accommodation establishments in the region; the exact number of catering establishments in MSK does not state, but according to the latest data of the CSO, there are 2.2 million seats in the region.

The Moravian-Silesian Region is very diverse, with many natural, cultural, technical, sports and other attractions; therefore, it is becoming an increasingly popular destination for tourists, which poses problems for sustainable tourism. In the next part of the paper, we focus primarily on the waste of food, which seems to be a significant problem that needs considerable attention.

We found out how the accommodation facilities deal with these problems in practice through pilot research, in which we obtained information from 18 subjects, mainly from $3 *$ hotels, among other facilities are spas. Below are results showing their approach to waste management, primarily with food.

The first graph (Figure 1) indicates the lack of registration of most of the accommodation facilities in EMAS, which is probably due to the lack of knowledge of many operators about the possibilities and benefits of membership.

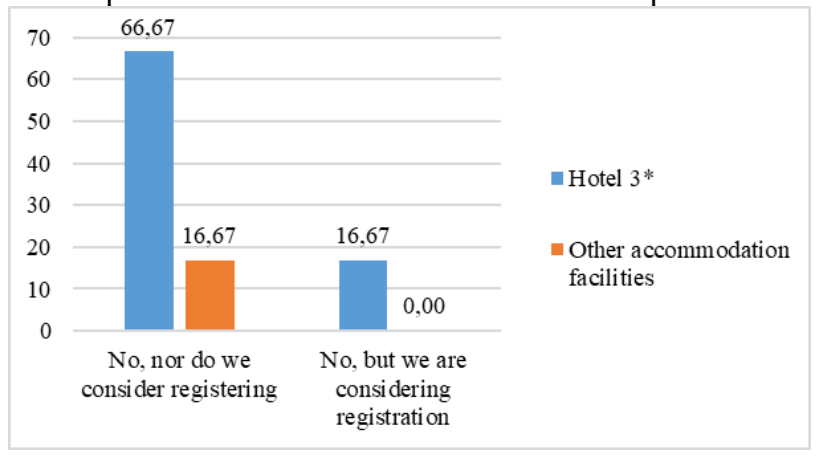

Fig. 1 Is the company register under EMAS?

The graph (Figure 2) shows the proportion of accommodation that sorts or at least partially sorts of waste. Those who did not answer the question of sorting waste answered that they sort waste in rooms and kitchens, so it can be assumed that about $70 \%$ of $3 *$ hotels sort waste. 


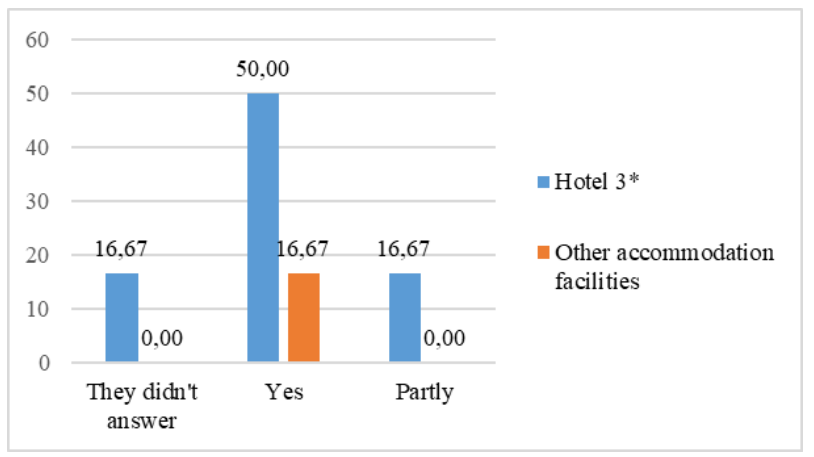

Fig. 2 Do you sort waste?

Respondents responded positively to use the possibility of reducing waste by efficient purchasing. Of course, according to Figure 3, it is clear that the hotel facilities have a large reserve here, although this is the primary source of possible waste.

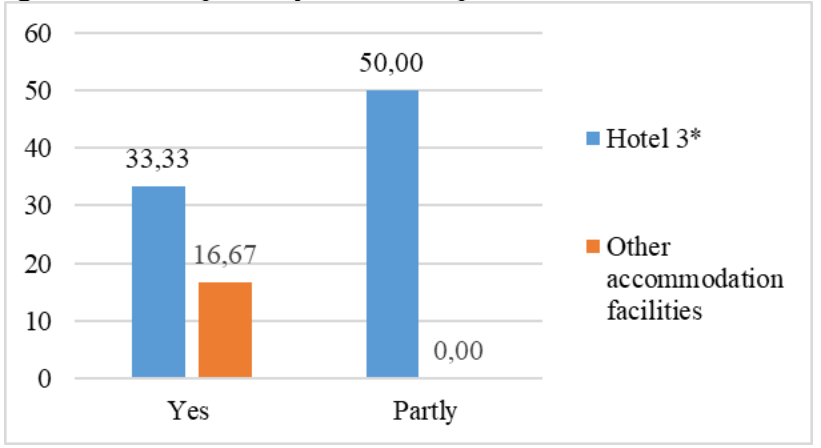

Fig. 3. Waste disposal: Are you trying to reduce waste by purchasing effectively?

There is also a commendable approach to staff and their leadership in waste reduction. Sixty percent of the facilities train their employees in the efficient use of food. Employees are trained to prevent waste in food preparation (Figure 4).

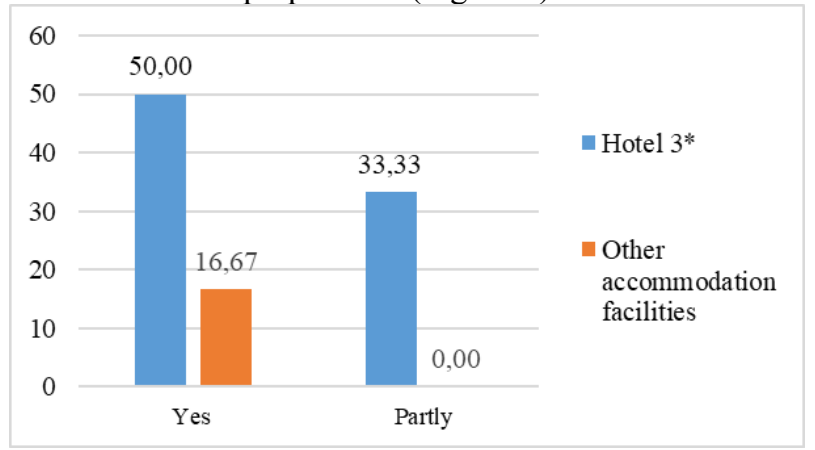

Fig. 4. Is the staff train to reduce waste in food preparation and cooking?

The graph (Figure 5) shows that operators have not yet sufficiently solved the prevention of perishable food. Hotel facilities often offer a full menu on buffet tables. A wide range of dishes is more attractive for the client, serving as a marketing tool. 


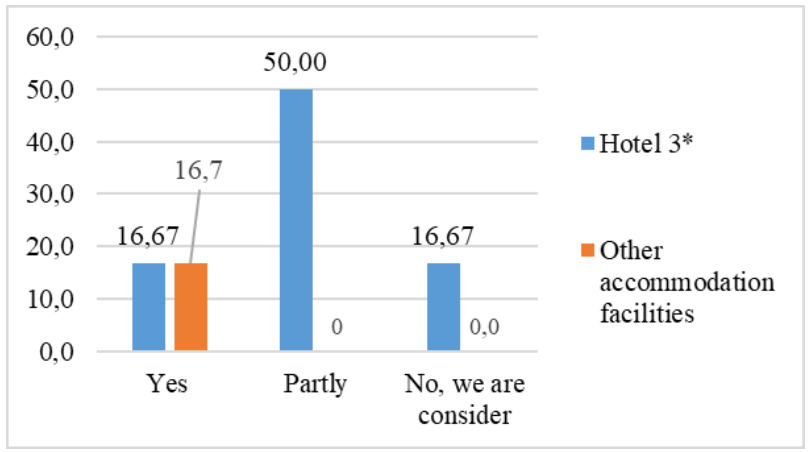

Fig. 5. Do you prevent food spoilage by not serving some products on buffet tables, but serving them on request?

A positive finding was that a more significant half of the respondents did not use disposable packs of food intended for the tables, which perhaps the rest of the respondents will start applying shortly.

Overall, although there are relatively large reserves in waste management, they are changing the attitudes of accommodation, catering facilities in a positive direction, and gradually increasing their responsibilities about sustainable tourism. If the generation of waste cannot be prevented, it is ideal to find a way to put it back into circulation, i.e. to make optimal use of it. If it cannot be prevented, it is ideal to find a way to put this waste back into circulation, i.e. how to make optimal use of it. The key to further waste management is to find the optimal solution; we can recycle everything. The question is at what price.

\section{Conclusion}

In recent years, increasingly addressing issues related to sustainable development and ecolabelled. If results are presented based on Ecolabel certificates, then the behavior of hotels seems unsustainable. At our institute, however, we believe that although hotels not only in the Moravian-Silesian Region are holders of the eco-label, most of them try to contribute to sustainable development and conservation of natural resources for future generations. However, it is essential to provide accommodation and catering establishments with a transparent methodology to manage energy, waste, water and more effectively reduce the negative impact on the environment.

Sustainable tourism could be contributed in future by other so-called smart tourist destinations, through a competition announced by the European Commission in line with the preparation of actions proposed by the European Parliament for the title of European Capital of Intelligent Tourism. Following the model of the European Capital of Culture, this initiative aims to select two European Capitals of Intelligent Tourism and four European Tourism Awards in categories: accessibility, sustainability, digitization, cultural heritage, and creativity. This new initiative rewards European cities allows them to share their exemplary practices as destinations for "intelligent tourism" and will present the achievements of EU-wide tourism destinations in the areas mentioned above. Of course, setting up methodologies, legislative frameworks and other formal measures are essential and necessary for sustainable tourism in the long run, but good examples are driving.

This paper is an output of the science project SGS 2/2019 "Tourism of the Moravian-Silesian Region in the context of sustainable development" Faculty of Philosophy and Science in Opava, Department of Spa, Gastronomy, and Tourism in Opava. 


\section{References}

1. P. Manomaivibool. Wasteful tourism in developing economy? A present situation and sustainable scenarios. Resources Conservation and Recycling 103, 8 (2015)

2. M. Sauer, J. Vystoupil, A. Holesinska, et al. Tourism. (EDP Masarykova Univerzita, Brno, 2009)

3. C. M. Hall. Constructing sustainable tourism development: The 2030 agenda and the managerial ecology of sustainable tourism. Journal of Sustainable Tourism 27, 7 (2019)

4. Ch. Yoopetch, S. Nimsai. Science Mapping the Knowledge Base on Sustainable Tourism Development 1990-2018. Sustainability 1, 13 (2019)

5. N. Vanhove. The Economics of Tourism Destinations. (EDP Elsevier, 2005)

6. J. Louda, J. Jilkova. Udrzitelny rozvoj - ekonomicky a politicky pohled. (EDP Alfa, Dolna Tizina, 2012)

7. K. Maier, J. Ctyroky. Sledovani a hodnoceni udrzitelneho rozvoje uzemi. (EDP Grada Publishing, Praha, 2012)

8. European Tourism Indicator System. (Luxembourg EU, 2013)

9. L. G. Block, P. A. Keller, et. al. The Squander Sequence: Understanding Food Waste at Each Stage of the Consumer Decision-Making Process. Journal of Public Policy \& Marketing 35, 13 (2016)

10. M. Eriksson, Ch. Malefors. The tree structure - A general framework for food waste quantification in food services. Resources Conservation and Recycling 130, 12 (2018)

11. B. Okumus. How do hotels manage food waste? registration from hotels in Orlando, Florida. Journal of Hospitality Marketing \& Management 28, (to be published)

12. E. Juvan, B. Gruen, S. Dolnica. Biting Off More Than They Can Chew: Food Waste at Hotel Breakfast Buffets. Journal of Travel Research 57, 11 (2018)

13. J. Aschemann-Witzel, I. de Hooge. Consumer-Related Food Waste: Causes and Potential for Action. Sustainability 7, 21 (2019)

14. V. Filimonau, M. Krivcova, F. Pettit. An exploratory study of managerial approaches to food waste mitigation in coffee shops. International Journal of Hospitality Management 76, 9 (2019)

15. L. Wang, L. Xue. Horeca food waste and its ecological footprint in Lhasa, Tibet, China. Resources Conservation and Recycling 136, 8 (2019)

16. N. Wright. Conceptual framework for the study of food waste generation and prevention in the hospitality sector. Waste Management 49, 11 (2016)

17. Business for Society. [online] [15. 8. 2019] Available at: https://narodnipotravinovasbirka.cz/co-je-food-waste/

18. Manual Association of Hotels and Restaurants of the Czech Republic „Food Waste“. (2019) 